ఠ

\title{
Meridional lenticular astigmatism associated with bilateral concurrent uveal metastases in renal cell carcinoma
}

This article was published in the following Dove Press journal:

Clinical Ophthalmology

5 November 2012

Number of times this article has been viewed

\section{Joshua C Priluck \\ Sandeep Grover \\ KV Chalam}

Department of Ophthalmology, University of Florida College of Medicine, Jacksonville, FL, USA
Correspondence: KV Chalam Department of Ophthalmology, University of Florida College of Medicine, 580 West 8th Street, Tower 2, Jacksonville, FL 32009, USA

Tel + I 904244936 I

Fax + I 904244939

Email kchalam@jax.ufl.edu
Purpose: To demonstrate a case illustrating meridional lenticular astigmatism as a result of renal cell carcinoma uveal metastases.

Methods: Case report with images.

Results: Clinical findings and diagnostic testing of a patient with acquired meridional lenticular astigmatism are described. The refraction revealed best-corrected visual acuity of 20/20-1 OD $(-2.50+0.25 \times 090)$ and 20/50 OS $(-8.25+3.25 \times 075)$. Bilateral concurrent renal cell carcinoma metastases to the choroid and ciliary body are demonstrated by utilizing ultrasonography, ultrawidefield fluorescein angiography, and unique spectral-domain optical coherence tomography.

Conclusions: Metastatic disease should be included in the differential of acquired astigmatism. Spectral-domain optical coherence tomography, ultrawidefield fluorescein angiography, and ultrasonography have roles in delineating choroidal metastases.

Keywords: astigmatism, metastasis, optical coherence tomography, renal cell carcinoma

\section{Introduction}

Renal cell carcinoma ( $\mathrm{RCC}$ ), a common malignant renal tumor, often metastasizes to the lung, bones, liver, and brain, and rarely to the eye. ${ }^{1}$ Common sites of intraocular metastasis within the eye include the choroid, iris, and ciliary body. ${ }^{2}$ We report an unusual case of meridional lenticular astigmatism with bilateral concurrent RCC metastases to the choroid and ciliary body, and describe spectral-domain optical coherence tomography (SD-OCT), ultrawidefield fluorescein angiography, and ultrasonography findings in the evaluation of the tumor.

\section{Case description}

A 63-year-old African American male presented with blurred vision of 6 months duration in his left eye. His medical history was significant for type 2 diabetes mellitus, coronary artery disease, hyperlipidemia, hypertension, and RCC. He was on renal dialysis secondary to chronic renal insufficiency, a consequence of nephrectomy, chemotherapy, and radiation for his RCC. His best-corrected visual acuity was 20/20-1 OD $(-2.50+0.25 \times 090)$ and $20 / 50$ OS $(-8.25+3.25 \times 075)$. Keratometry measured 45@89/44.5@179 OD and 45@18/45@108 OS. Corneal topography was normal. Slitlamp biomicroscopy revealed few keratic precipitates for OS, mild 1+ nuclear sclerotic cataract, and a lesion posterior to the lens (Figure 1). Gonioscopy revealed 3 clock hours of angle crowding temporally, which was confirmed on anterior segment OCT (Slit-lamp OCT, Heidelberg Engineering, Heidelberg, Germany). Fundoscopy of the 


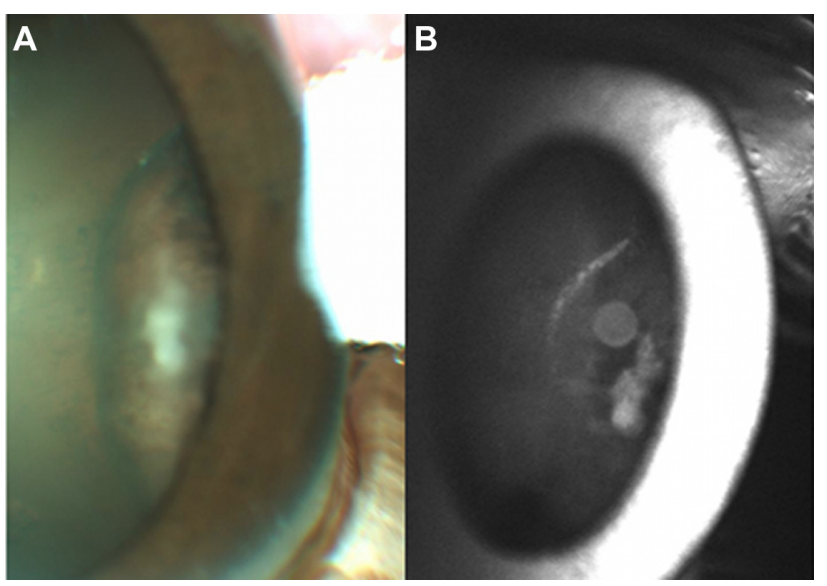

Figure I Slit-lamp findings demonstrate keratic precipitates in the left eye, I+ nuclear sclerotic cataract, and a ciliary body lesion.

Note: Crowding of the temporal angle was apparent.

right eye revealed a hypopigmented elevated lesion at the inferior disc margin $(4.5 \mathrm{~mm} \times 4 \mathrm{~mm})$. Fundoscopy of the left eye revealed an elevated circumscribed lesion anterior to the equator encroaching on the ciliary body, with crowding of the angle at the 9 o'clock meridian.

The right peripapillary lesion measured $7.06 \mathrm{~mm} \times 7.10 \mathrm{~mm} \times 3.06 \mathrm{~mm}$ on ultrasound. A second mass located nasally measured $5.53 \mathrm{~mm} \times 6.06 \mathrm{~mm} \times 2.33 \mathrm{~mm}$. Fluorescein angiography revealed few scattered microaneurysms, with mild focal leakage and staining that extended over the disc in the right eye. SD-OCT of the right eye demonstrated a peripapillary lesion with a dome-like elevated retina, areas of thickened nerve fiber layer, subretinal fluid, and retinal pigment epithelium hyperplasia (Figure 2) (Spectralis HRA + OCT, Heidelberg Engineering).

The left ciliary body lesion measured $6.06 \mathrm{~mm} \times 5.53 \mathrm{~mm} \times 2.23 \mathrm{~mm}$ by ultrasonography. Wide-angle angiography (with Staurenghi 230 SLO retina lens, Spectralis HRA + OCT) revealed an irregularly staining hyperfluorescent lesion anterior to the equator in the temporal region (Figure 3). The anterior edge of the mass
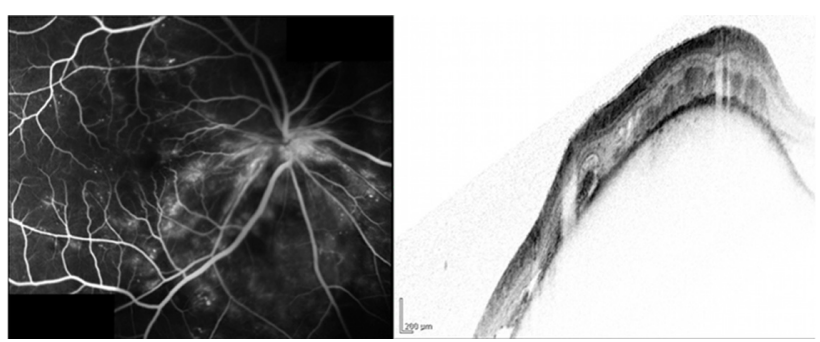

Figure 2 Fluorescein angiogram and corresponding spectral-domain optical coherence tomography image of peripapillary renal cell carcinoma metastasis of the right eye.

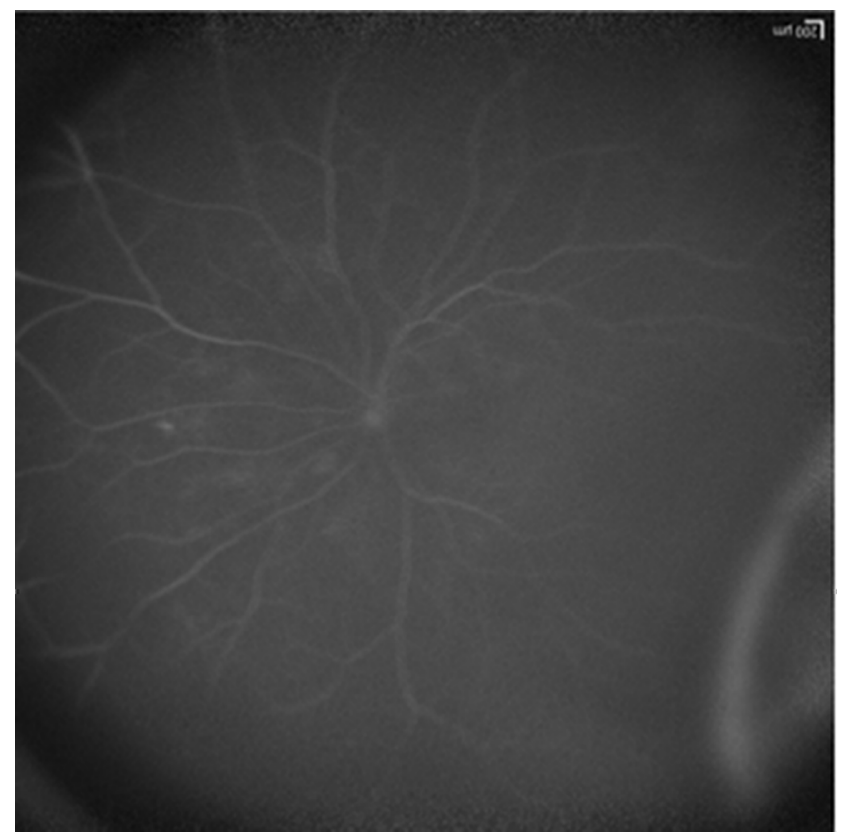

Figure 3 Ultrawidefield angiography of the left eye demonstrates irregularly staining hyperfluorescent lesion anterior to the equator in the temporal region.

crowded the angle and induced lenticular astigmatism $(-8.25+3.25 \times 075)$. An ultrasound showed a "mass with medium to high internal reflectivity." The patient was offered orbital radiation to alleviate the metastasis but declined.

\section{Comment}

RCC, the most common renal neoplasm, often metastasizes through lymphatic and venous routes to the lung parenchyma $(50 \%-60 \%)$, bone $(30 \%-40 \%)$, liver $(30 \%-40 \%)$, and brain $(5 \%)^{3}$

Ocular metastasis from primary RCC is extremely rare. ${ }^{1}$ To date, only 34 cases of uveal metastases were reported; only two were bilateral and none was concurrent. ${ }^{2,4,5}$

Bilateral simultaneous uveal involvement and associated anterior meridional lenticular astigmatism make our case unique. Ciliary body metastasis induced a myopic shift and meridional lenticular displacement (refractive error from -2.50 sphere to $-8.25+3.25 \times 075$ in 12 months). This astigmatism, not explained by keratometry, indicates that the ciliary body mass is causing tilting of the lens and induced astigmatism. Clinicians discovering new astigmatism and myopic changes should consider occult metastasis in their differential diagnosis.

Ultrawidefield fluorescein angiography detailed the far peripheral lesion in our patient's left eye. The lesion had irregular hyperfluorescent staining and was located anterior to the equator in the temporal region. 
SD-OCT may offer an important method of following choroidal metastasis compared with traditional B-scan ultrasonography and previous-generation OCT as the resolution continues to improve. Time-domain OCT of different choroidal metastasis revealed retinal and retinal pigment epithelial changes with overlying subretinal fluid. ${ }^{6}$ The high quality of SD-OCT scans demonstrates the lesion's position relative to the optic nerve, dome shape, size, and associated subretinal fluid.

\section{Conclusion}

We report a unique case of simultaneous bilateral uveal metastases of RCC with a concurrent ciliary body metastasis that induced myopic shift and meridional astigmatism from displacement of the crystalline lens.

\section{Disclosure}

None of the authors has a conflict of interest with the submission. No financial support was received for this submission.

\section{References}

1. Ferry AP, Font RL. Carcinoma metastatic to the eye and orbit II. A clinicopathological study of 26 patients with carcinoma metastatic to the anterior segment of the eye. Arch Ophthalmol. 1975;93(7):472-482.

2. Shome D, Honavar SG, Gupta P, Vemuganti GK, Reddy PV. Metastasis to the eye and orbit from renal cell carcinoma: a report of three cases and review of literature. Surv Ophthalmol. 2007;52(2):213-223.

3. Thyavihally YB, Mahantshetty U, Chamarajanagar RS, Raibhattanavar SG, Tongaonkar HB. Management of renal cell carcinoma with solitary metastasis. World J Surg Oncol. 2005;3:48.

4. Haimovici R, Gragoudas ES, Gregor Z, Pesavento RD, Mieler WF, Duker JS. Choroidal metastases from renal cell carcinoma. Ophthalmology. 1997;104(7):1152-1158.

5. Elghissassi I, Inrhaoun H, Ismaili N, Errihani H. Choroidal metastasis from tubulopapillary renal cell carcinoma: a case report. Cases $J$. 2009;2:6681.

6. Arevalo JF, Fernandez CF, Garcia RA. Optical coherence tomography characteristics of choroidal metastasis. Ophthalmology. 2005;112(9):1612-1619.
Clinical Ophthalmology

\section{Publish your work in this journal}

Clinical Ophthalmology is an international, peer-reviewed journal covering all subspecialties within ophthalmology. Key topics include: Optometry; Visual science; Pharmacology and drug therapy in eye diseases; Basic Sciences; Primary and Secondary eye care; Patient Safety and Quality of Care Improvements. This journal is indexed on

Submit your manuscript here: http://www.dovepress.com/clinical-ophthalmology-journal

\section{Dovepress}

PubMed Central and CAS, and is the official journal of The Society of Clinical Ophthalmology (SCO). The manuscript management system is completely online and includes a very quick and fair peer-review system, which is all easy to use. Visit http://www.dovepress.com/ testimonials.php to read real quotes from published authors. 